\title{
The development of integrated real time control to optimise storm water management for the combined sewer system of Rome
}

\author{
R. Celestini ${ }^{1}$, G. Silvagni ${ }^{2} \&$ F. Volpi ${ }^{2}$ \\ ${ }^{1}$ Acea Ato2 S.p.A., Italy \\ ${ }^{2}$ Department of Civil Engineering and Computer Science Engineering, \\ University of Rome "Tor Vergata", Italy
}

\begin{abstract}
Increasing urbanisation and intensification of human activities are common trends all over the world. The higher portion of impermeable urban surfaces often leads to well known effects on storm water runoff and its polluting potential for receiving waters. Despite the variety of structural solutions and management practices proposed to mitigate the operational and environmental impact of urban runoff, their application on existing drainage systems can often be either ineffective at a metropolitan scale or unfeasible for a densely urbanised territory. Among all the proposed alternatives, the real time control (RTC) of drainage systems is proving more and more promising to dynamically regulate the system capacity in response to intense rainfall. The combined sewer network of Rome, historically built with high-capacity pipes to collect storm water from both urban and natural catchments, holds significant potential for RTC of online storage and combined sewer overflows, to optimise the global drainage capacity and reduce the impact of discharges on local river quality. To assess the real benefits, the potential limits and the feasibility of such a system for the city sewers, a pilot study has been conducted on a 3,000 hectare sub-catchment. It involved the development of a fast-response hydrodynamic simulation tool for the sewer network, the definition and evaluation of RTC strategies and the implementation of an environmental integrated telemetry system. As described here, the study has highlighted significant margins for the optimisation of the global network capacity without any major interventions on the physical assets, as well as some critical issues to solve for a fully operational RTC application. Keywords: real time control, urban drainage, combined sewers, CSO.
\end{abstract}




\section{Introduction}

While the initial target of wastewater treatment technologies was limited to reducing the chronic pollution generated by domestic and industrial discharges on receiving bodies, only in the last decades the densification of urban fabric in the biggest cities has forced the scientific world to recognise storm water as a significant source of impulsive pollution.

Often metropolitan sewers were historically developed as combined systems to drain surface waters as well as to collect domestic discharges. Hence the need for combined sewer overflows (CSOs) to separate sewage to be treated from diluted water to be spilled, which introduced an inevitable direct connection between urban wastewater and receiving water bodies. The initial design criteria for CSO systems generally considered storm-water as clean water useful to dilute sewage. More recent approaches, however, have recognised the significant polluting potential of urban runoff, particularly concentrated in the water volumes drained during the initial part of storm events (Nationwide Urban Runoff Program, USEPA, 1983; Urban Pollution Management Manual, FWR, 1995 and following editions; European Directive 2000/60/EC, Water Framework Directive; etc.). In particular, the inorganic polluting material transported by runoff from urban surfaces, in addition to the domestic sewage sediment eroded by storm waves, are common causes for first flush effects in combined sewers which, if unmitigated, can represent a threat for aquatic habitats in CSO receiving bodies (Lee and Bang [1]; Bertrand-Krajewski et al. [2]).

The growing scientific interest in storm-water pollution highlighted the need for its advanced and more sustainable management. Different approaches have been proposed, therefore, to counter the effects of the general urbanisation of runoff surfaces. From the definition and design of Best Management Practices (BMPs), diffused over the drainage basin, to the introduction of major online storage devices within the sewer system, the aim is the reduction, delay and/or quality improvement of storm water discharges.

The other form of advanced storm water management herein discussed, not necessarily alternative to other methods, is the dynamic use of the whole sewer network hydraulic capacity by means of real time control (RTC) of electromechanical devices. RTC approaches to storm water management could represent the most effective option in well established city systems, where BMPs cannot extensively replace traditional drainage and intense urban fabric does not always offer suitable areas to host storage structures. The potential of such a system, aimed at constantly regulating the water flow in different parts of a network based on global real time information, lays in its ability to adapt over space and time the entire drainage capacity to rapidly evolving storm events (Campisano and Sanfilippo [3]; Rauch and Harremoës [4]).

While the first attempts to introduce automatic volume control in sewers started a few decades ago, following its boom in other industrial sectors, most full-scale drainage systems, with some relevant exceptions, are still mainly based on the well-tested criteria of static hydraulic constructions. The reasons for such 
a slow introduction of RTC in drainage systems are various, from the significant extent over the territory of the telemetry systems involved, to the higher maintenance costs, as well as the potential safety issues connected to malfunctions. One of the greatest impediments, however, is possibly the need for a definite change in management mentality and staff competencies required. On the other hand, the recent trend in international environmental legislation is generally to introduce more stringent requirements in storm water management. This, combined with the higher reliability and accessibility of telemetry systems, is making RTC a more viable option.

The main sewer system of Rome, with its millenary tradition of hydraulic engineering, shows promising attributes for the application of innovative storm water management. The current configuration of its sewers is the result of progressive integrations and modifications of canals and pipes from different centuries. Starting from the first open channels built during the reign of the Etruscan kings $\left(6^{\text {th }}\right.$ century BC), to the major interventions on the Roman sewers performed during the Middle Ages and up to modern days, the system always had a strong connection with storm water and the local streams and rivers (Margaritora et al. [5]). If nowadays, on the one hand, Roman sewers generally drain high volumes of storm water and intercept most local natural streams, with obvious complications for wastewater management, on the other hand their size, extension and level of interconnection are typical features which can ensure significant potential for online storage (Borsànyi et al. [6]; Campisano and Sanfilippo [3]; DWA [7]). Based on this general idea, the municipality of Rome started considering the use of dynamic flow regulation during the nineties, and Acea ATO2, the local water and wastewater utility since 2003, made the first steps in this direction by enhancing their telemetry system and conducting further analysis on the potential benefits of RTC.

\section{The drainage system of Rome: first steps towards RTC}

\subsection{The pilot catchment}

The present research, conducted by Acea S.p.A. with the cooperation of the University of Rome "Tor Vergata", aimed at defining and analysing potential approaches to optimise complex drainage networks by means of RTC strategies. Particular attention was given to evaluating all the main aspects of RTC implementation on a traditionally operated sewer system. Hence the pilot catchment selected within the city network was supposed to be representative of the whole system, with regard to extension, co-existence of urban and natural sub-basins, type of pipes, presence of CSO chambers, connections to the rivers, and existence of centralised telemetry.

The chosen area, north-east of the city centre and along the river Aniene, is the "Cesarina-San Basilio-Bufalotta" catchment, with a surface of about 3,000 ha, a population of over 100,000 people and a sewer network branched in three main sub-networks, each ending with a CSO structure and all regulated downstream by the same pumping station, which conveys wastewater towards one of the primary WWTPs of Rome (see Figure 1). 

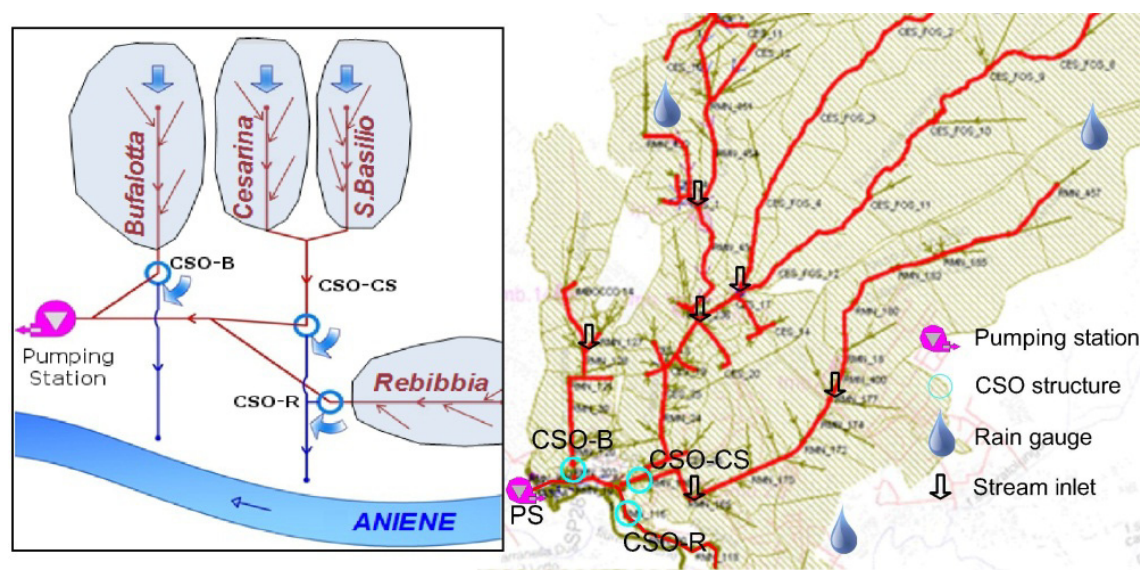

Figure 1: Graph structure of the sewer network and its model.

Table 1: Description of the three main sub-catchments.

\begin{tabular}{|c|c|}
\hline 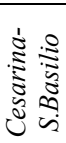 & $\begin{array}{l}\text { This basin is the largest ( } 2800 \text { ha, } 75,000 \text { inhabitants); approximately divided in an upper } \\
\text { natural area and a lower densely populated city area; its terminal channels leading to the } \\
\text { CSO chamber (CSO-CS), with } 18 \text { sqm rectangular sections } 0.1 \% \text { gradients, offer the } \\
\text { greatest volume for online water retention. }\end{array}$ \\
\hline$\frac{\sqrt[5]{0}}{\frac{5}{0}}$ & $\begin{array}{l}\text { With a } 300 \text { ha surface, } 23,000 \text { inhabitants, } 9 \text { sqm egg-shaped terminal pipe and a smaller } \\
\text { CSO chamber }(C S O-B) \text {, it globally drains smaller water volumes than the previous basin; } \\
\text { its averagely higher slope implies shorter concentration times and more impulsive storm } \\
\text { waves. }\end{array}$ \\
\hline 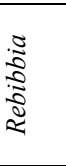 & $\begin{array}{l}\text { With } 130 \text { ha and } 10,000 \text { people, it is served by a low-gradient combined sewer; its } \\
\text { terminal } 4.5 \text { sqm egg-shaped pipe and its } C S O-R \text { are highly influenced by the limited } \\
\text { downstream system capacity, with frequent backflow events. Because of their hydraulic } \\
\text { interconnection, } C S O-R \text { and } C S O-C S \text { are here analysed as a single overflow complex } \\
(C S O-C S+R) \text {. }\end{array}$ \\
\hline
\end{tabular}

The main sub-basins are completely served by tree-structured combined sewers, without any close-circuit connections (see Table 1).

The most representative features of the pilot catchment sewers are the following:

- all CSOs statically regulate storm water spills to the river Aniene by means of permanent frontal weirs, set to ensure a minimum dilution ratio of at least five times the average dry weather flow, according to national and regional standards;

- $\quad$ there are no online storage tanks, apart from the buffering volume at the pumping station; the construction of additional tanks is not feasible due to the lack of available areas; the only storage capacity is offered by the sewer channels themselves;

- holding a cumulative rated power of over $500 \mathrm{kw}$ and a maximum flow capacity of $4,000 \mathrm{l} / \mathrm{s}$, the pumping station works in a traditional way, 
with four submersible pumps which progressively turn on depending on the local water level, and two screw pumps which work alternatively.

A thorough analysis of the described system's hydraulics during wet weather showed its general accordance to the current environmental quality standards locally set for CSO discharges. However it also showed significant potential for optimisation of the system drainage capacity during rain events.

\subsection{Metering and modelling}

In order to study the system behaviour during wet weather, the pilot catchment has been equipped with a series of measuring devices. As the evaluation of structural and operational interventions on the system for its optimisation requires a deep knowledge and hydrological/hydraulic modelling, a wide range of online and offline data has been collected thanks to ultrasound level gauges and radar-ultrasound flow rate metres. Furthermore, rainfall data was collected from three local pluviometers out of the city network stations, with 10 minute time step cumulated rainfall measurements.

Representing and forecasting the system response to rain events necessarily requires hydrodynamic modeling of the primary sewer network. With the support of Acea S.p.A.'s staff, a series of surveys was therefore conducted to integrate the topographic and geometric data already available, in order to create a representative model for the pilot catchment (see Figure 1). For its implementation, and for the simulation of gradually varied flow generated in the system by the combination of domestic discharges and wet weather runoff, the software Infoworks $C S^{\circledR}$ (Innovyze ${ }^{\circledR}, H R$ Wallingford) was chosen among the existing platforms. The model was tested and calibrated under the current configuration, based on data collected by the above listed tools during a dedicated series of measurements.

\subsection{Definition of RTC scenarios}

Following a detailed analysis of the current configuration, a series of alternative RTC scenarios were defined and tested to optimise the urban drainage system in the pilot catchment. Their effectiveness essentially relies on the following criteria:

- static sewer configurations and traditionally operated actuators are normally designed to ensure drainage standards for the most critical state of the system, over-performing during the rest of the time;

- rainfall intensity centres generally move rapidly over the territory of Rome, therefore different sewer basins could reach peak runoff at different times during the same event;

- out of multiple sub-basins sharing the same downstream receiving sewer, RTC could favour one basin's drainage performance at the expense of another's, based on real time data and CSO significance;

- within the pilot sewer network, $C S O-B$ can be rated as "less sensitive" than $\mathrm{CSO}-\mathrm{CS}+\mathrm{R}$, as in its current static configuration it generally overperforms, and its typical runoff shows less significant polluting loads. 
Table 2: RTC scenarios.

\begin{tabular}{|c|c|c|}
\hline \multirow{5}{*}{ | } & $\begin{array}{l}\text { Control } \\
\text { Variables }\end{array}$ & $\begin{array}{l}\text { a) Water depth in pumping station's buffer tank } \\
\text { b) Rain intensity }\end{array}$ \\
\hline & Actuators & Existing pumps \\
\hline & $\begin{array}{l}\text { Control } \\
\text { rules }\end{array}$ & $\begin{array}{l}\text { a) Standard level-based control of pumps, unless: } \\
\text { b) If avg cumulated rainfall over the pilot catchment reaches } 3 \mathrm{~mm} \text { in } 10 \\
\text { min then all pumps concur to empty buffer tank (feedforward - } \\
\text { proportional derivative (PD) control). }\end{array}$ \\
\hline & Extension & Local control of actuators based on global and integrated set of data. \\
\hline & Objective & Maximization of storm water storage at pumping station. \\
\hline \multirow{5}{*}{ نे } & $\begin{array}{l}\text { Control } \\
\text { Variables }\end{array}$ & $\begin{array}{l}\text { a) See Scenario A } \\
\text { b) flow rate upstream of } C S O-B\end{array}$ \\
\hline & Actuators & $\begin{array}{l}\text { a) Existing pumps; } \\
\text { b) Remote controlled sluice gate (to be installed } C S O-B \text { downstream pipe) }\end{array}$ \\
\hline & $\begin{array}{l}\text { Control } \\
\text { rules }\end{array}$ & $\begin{array}{l}\text { a) See Scenario A } \\
\text { b) If water volume sent to treatment through sluice gate reaches min. legal } \\
\text { threshold ( } 50 \mathrm{~m}^{3} \text { per ha of impermeable surface) then sluice gate is } \\
\text { regulated to min. capacity and exceeding flow is spilled to the river } \\
\text { (feedback and feedforward-proportional integral derivative control). }\end{array}$ \\
\hline & Extension & Local control of actuators based on global and integrated set of data. \\
\hline & Objective & $\begin{array}{l}\text { Minimization of spills from } \mathrm{CSO}-\mathrm{CS}+\mathrm{R} \text { once } \mathrm{CSO}-\mathrm{B} \text { has fulfilled legal } \\
\text { requirements. }\end{array}$ \\
\hline \multirow{5}{*}{ نे } & $\begin{array}{l}\text { Control } \\
\text { Variables }\end{array}$ & $\begin{array}{l}\text { a) See Scenario A; } \\
\text { b) filling degree of } C S O-C S+R \text { receiving pipe }\end{array}$ \\
\hline & Actuators & See Scenario B \\
\hline & $\begin{array}{l}\text { Control } \\
\text { rules }\end{array}$ & $\begin{array}{l}\text { a) See Scenario A } \\
\text { b) If pipe filling degree in } C S O-C S+R \text { receiving pipe reaches } 80 \% \text { of } \\
\text { section height then sluice gate by } C S O-B \text { is regulated to minimum } \\
\text { capacity }(\text { feedback and feedforward }-P D)\end{array}$ \\
\hline & Extension & Global control of actuators based on global and integrated set of data. \\
\hline & Objective & Flow from $\mathrm{CSO}-\mathrm{CS}+\mathrm{R}$ has priority in downstream system capacity. \\
\hline \multirow{5}{*}{ el } & $\begin{array}{l}\text { Control } \\
\text { Variables }\end{array}$ & $\begin{array}{l}\text { a) See Scenario A; } \\
\text { b) filling degrees of both } C S O-C S+R \text { and }-B \text { receiving pipes }\end{array}$ \\
\hline & Actuators & See Scenario B \\
\hline & $\begin{array}{l}\text { Control } \\
\text { rules }\end{array}$ & $\begin{array}{l}\text { a) See Scenario A } \\
\text { b) the sluice gate by CSO-B is iteratively regulated in order to keep filling } \\
\text { degree in } C S O-C S+R \text { receiving pipe equal to } C S O-B \text { 's (feedback and } \\
\text { feedforward }-P D \text { control). }\end{array}$ \\
\hline & Extension & Global control of actuators based on global and integrated set of data. \\
\hline & Objective & $\begin{array}{l}\text { Equalization of contributions from all sub-basins to downstream system } \\
\text { flow. }\end{array}$ \\
\hline
\end{tabular}

RTC scenarios described in Table 2 offer a range of possible interventions on the current system; although characterised by an increasing level of control complexity, they were all defined according to the following general objectives:

- mitigation of CSO quality impact on receiving waters (improvement of dilution ratios of discharged combined sewage);

- $\quad$ reduction of unnecessary WWTP load;

and considering the following constraints:

- $\quad$ public safety, which implies fail safe control rules and actuators, as well as simple strategies, to enable human supervision (hence the option of full optimisation through the use of objective functions was discarded); 
- $\quad$ cost (which influences the number of actuators and signals);

- $\quad$ staff training and management commitment (gradual application).

\subsection{Evaluation of RTC scenarios}

The performance of the pilot drainage network under the proposed RTC scenarios was evaluated in detail and compared to the current configuration thanks to an extensive series of simulations under a wide range of rainfall input.

To test the system under representative conditions, the first simulations aimed at analysing its response to synthetic Chicago-type rainfall distributions, with intensity given by the following expression, based on the two-component extreme value (TCEV) distribution suggested by the Italian VAPI project:

$$
i(t)=\frac{a(T)}{(b+t)^{m}}
$$

where $t$ is the duration of the rainfall event, $a, b$ and $m$ are geographical parameters and $T$ is the return time.

As the purpose was the evaluation of critical yet frequent storm events, the simulations were run under the following characteristic rain events:

1. uniform; $\mathrm{T}=1.5 \mathrm{yrs} ; i_{\max }=120 \mathrm{~mm} / \mathrm{h}$, Duration $(\mathrm{D})=1$ hour;

2. moving from west to east (affecting in sequence the Bufalotta basin first, then Cesarina-San Basilio and Rebibbia); $\mathrm{T}=1.5 \mathrm{yrs} ; \mathrm{D}=1 \mathrm{hr}$;

3. moving from east to west; $\mathrm{T}=1.5 \mathrm{yrs} ; \mathrm{D}=1 \mathrm{hr}$;

4. moving from west to east; $\mathrm{T}=0.5 \mathrm{yrs}, i_{\max }=90 \mathrm{~mm} / \mathrm{h} ; \mathrm{D}=1 \mathrm{hr}$.

The simulation results confirmed how the proposed RTC scenarios can significantly influence the hydraulic behaviour of the analysed drainage network. They also highlighted, however, that their effectiveness is strongly dependent on how each storm event develops, more than on how intense it is. In particular, in the occurrence of storms moving over the catchment surface, the sub-basin initially subject to runoff tends to saturate the downstream system capacity first, reducing the performance of the remaining "competing" CSOs. This tendency is accentuated when runoff first occurs in the Bufalotta basin, already characterised by shorter concentration times; consequently, actions aiming at delaying or reducing the volume of storm water sent to treatment through $C S O-B$ in favour of $C S O-C S+R$ have proven the most effective. Furthermore, it is clearly shown that RTC Scenario A, which only tends to maximize the buffer volume at the pumping station in case of rain, offers limited benefit, as the water volumes involved are generally much greater than the capacity offered by the tank.

Figure 2, where overall CSO spilled volumes during different synthetic rain events are shown for $C S O-B$ and the combination of $C S O-C S+R$, confirms how the general effect of proposed RTC scenarios $B-D$ is to reduce the discharged volume from the latter by increasing it from the former. In most cases, though, as a direct effect of the RTC strategies, while the reduced volume discharged by $C S O-C S+R$ corresponds to the initial portion of the storm wave, the additional volume discharged by CSO-B is distributed along the whole event.

As an example, Figure 3 shows the pattern of spilled flow rate for both CSO$\mathrm{CS}+\mathrm{R}$ and $\mathrm{CSO}-\mathrm{B}$ in the case of rain event 2, for the different RTC scenarios. 


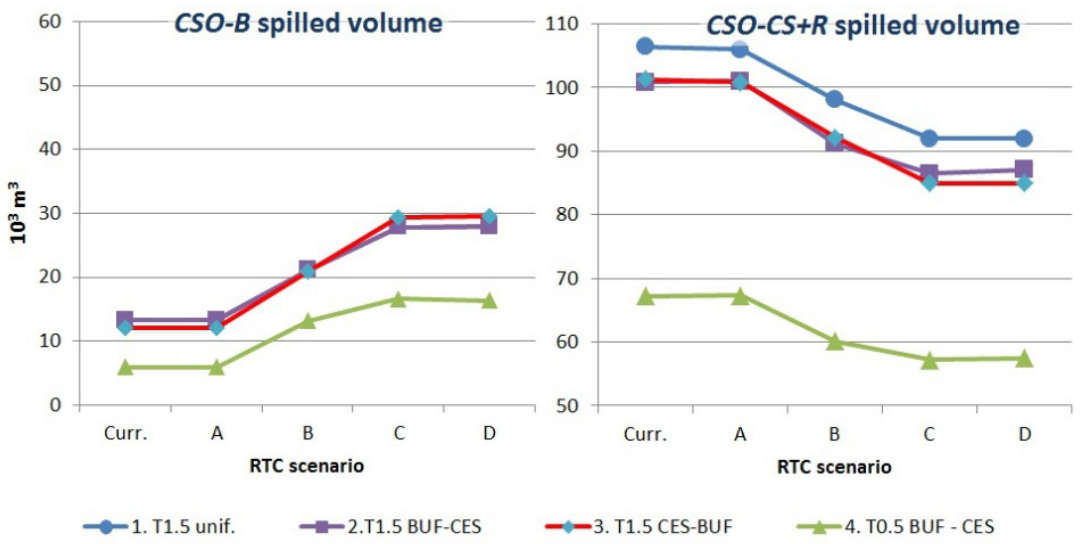

Figure 2: Volumes spilled to receiving waters.
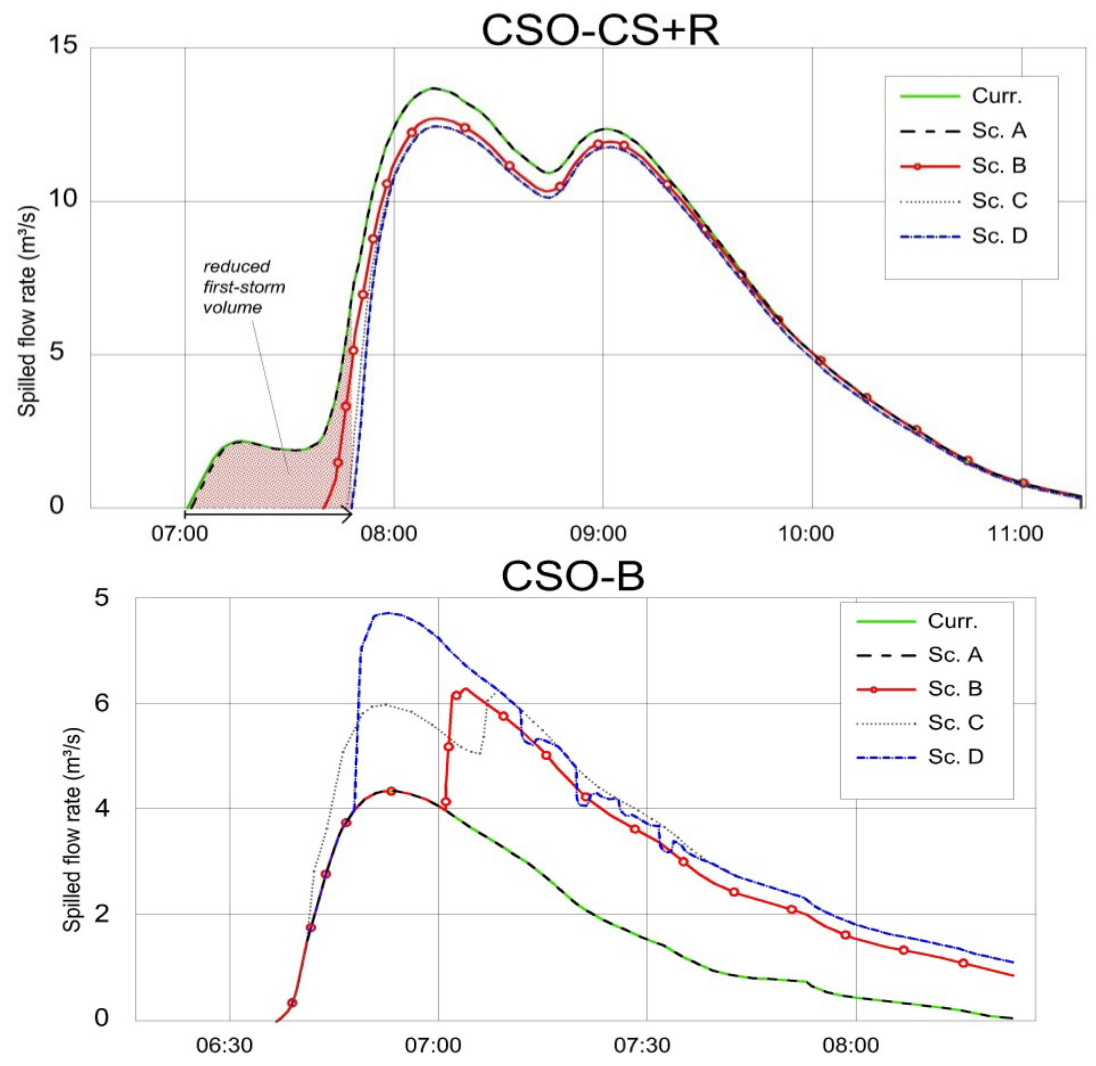

Figure 3: CSOs to receiving waters during synthetic rain event 2. 
The reduction in volume of spilled first-storm water for CSO-CS+R, from the current situation to Scenario $\mathrm{D}$, is represented by the highlighted area in the graph and equals $6200 \mathrm{~m}^{3}, 6.3 \%$ of the total spilled volume. Such reduction, as an effect of CSO delay, is concentrated in the first-flush phase of the wave, aiming at reducing impact on the river quality. At the same time, instead, the additional volume spilled at CSO-B in the case of Scenarios B-D affects later stages of the storm wave, leaving the initial CSO pattern essentially unmodified and therefore not worsening its polluting impact.

The advantage of this dynamic re-adjustment of sewer capacity is clear when considering Figure 4, which shows the dilution ratio (design parameter used in Italian environmental legislation to measure compliance to $\mathrm{CSO}$ quality standards) calculated for $\mathrm{CSO}-\mathrm{B}$ and $\mathrm{CSO}-\mathrm{CS}+\mathrm{R}$ at the instant of initial overflow, given by the ratio of incoming flow to the average dry weather flow.

Apart from the characteristic rain event 3, RTC scenarios $B-D$ all tend to significantly improve dilution ratios for $C S O-C S+R$ (generally just above required standards), thus reducing their environmental impact, while only marginally reducing $C S O-B$ ratios (already high).
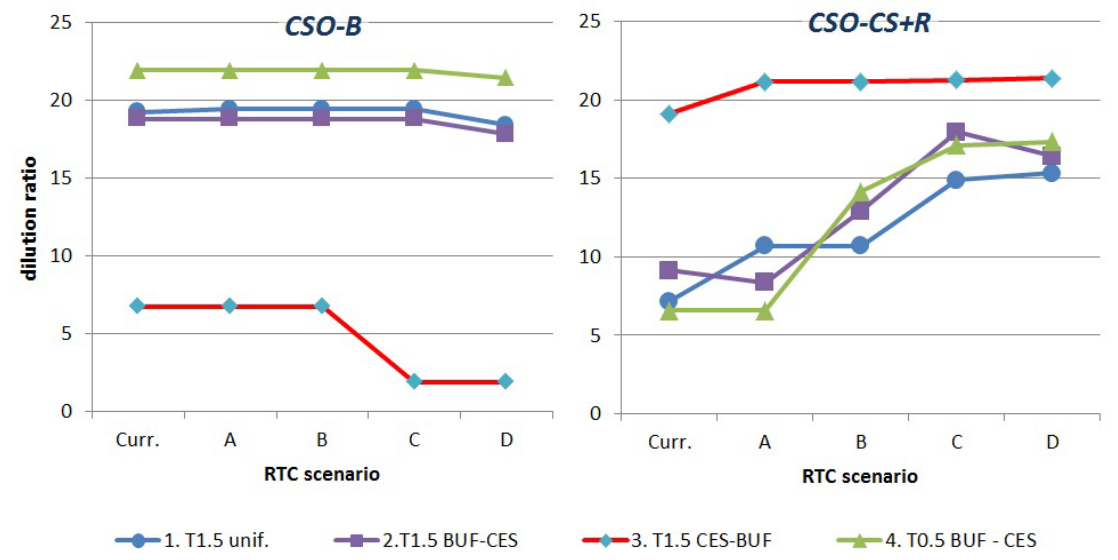

Figure 4: CSO dilution ratios at initial discharge (synthetic events).

Only with storm case 3, which hypothesises a storm affecting the Bufalotta basin last, RTC scenarios $C-D$ result in a definite worsening of $C S O-B$ performance, even bringing its dilution ratio below the minimum legal requirement of 5 .

In order to judge the effectiveness of the proposed scenarios under real conditions, a long-term campaign of simulations was conducted using measured rainfall input. In particular, the results reported below refer to the following characteristic events registered by the three rain gauges during 2011, in increasing order of cumulated rainfall: 
- $\quad 3^{\text {rd }}$ May; $i_{\max }=20.5 \mathrm{~mm} / \mathrm{h}$; cumulated rainfall $(\mathrm{CR})=6.5 \mathrm{~mm}$;

- $\quad 25^{\text {th }}$ April; $\mathrm{i}_{\max }=10.8 \mathrm{~mm} / \mathrm{h} ; \mathrm{CR}=11.0 \mathrm{~mm}$;

- $\quad 16^{\text {th }}$ February; $\mathrm{i}_{\max }=31.8 \mathrm{~mm} / \mathrm{h} ; \mathrm{CR}=12.5 \mathrm{~mm}$;

- $\quad 14^{\text {th }}$ May; $i_{\max }=36.6 \mathrm{~mm} / \mathrm{h} ; \mathrm{CR}=13.5 \mathrm{~mm}$;

- $\quad 21^{\text {st }}$ May; $\mathrm{i}_{\max }=36.6 \mathrm{~mm} / \mathrm{h} ; \mathrm{CR}=19.0 \mathrm{~mm}$.
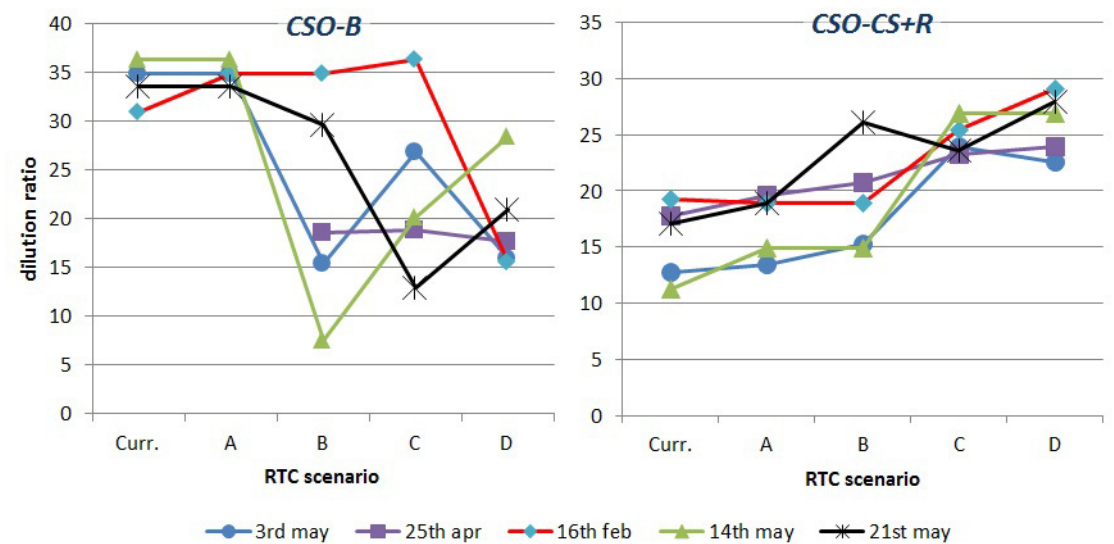

Figure 5: CSO dilution ratios at initial spill (measured events).

As shown in Figure 5, the system's response to real storm events is obviously less predictable than under theoretical conditions. From a combined analysis of both sets of results, however, it is possible to draw the following conclusions:

- $\quad$ RTC scenarios from $A$ to $D$, introducing progressively more extensive types of dynamic control, generally show a gradual and definite improvement of $C S O-C S+R$ performance, considered primary;

- the corresponding performance of CSO-B worsens heterogeneously, depending on the geographical development of each storm; in most cases its performance remains very high;

- scenarios $C$ or $D$ would ensure noticeable improvement in the overall performance of the system during wet weather, apart from the only occurrence of storm events moving from east to west, in which case the RTC strategy should switch to Scenarios $A$ or $B$.

Despite the improvement offered by the proposed RTC strategies in measurable performances according to CSO design criteria, however, it is interesting to notice how the same strategies produce different effects on water quality impact depending on the particular storm event. With reference to CSO$C S$ catchment, the most important for size and water quality impact, further studies on its storm water quality have shown highly variable first-flush intensity depending on factors such as the length of the dry period before each storm or the occurrence of persistent rainfall over the upstream natural basin. Figure 6, comparing the observed variability of TSS and COD first-flush intensity for the Cesarina-S.Basilio runoff against the characteristic Bertrand-Krajewski curves 
(Bertrand-Krajewski et al. [2]), clearly shows how the same reduction in initial overflow volume can offer a wide range of benefits in terms of reduced mass of spilled pollutants: $10 \%$ CSO volume reduction prior to the initial spill could reduce the corresponding mass of TSS sent to the river by a quantity ranging from $1 \%$ to $16 \%$, and the mass of COD by $3 \%$ to $22 \%$. Although first-flush events in the analysed basin are still more frequent than the last-flush ones, the periodical occurrence of the latter shows a behaviour less typical of urban areas and more characteristic of large heterogeneous catchments, which cannot be ignored when evaluating major interventions on the drainage system.

In fact, such a behaviour shows how in the future an integrated water-qualitydriven RTC system, able to activate optimal control strategies depending on a comprehensive set of online system information, could be the best answer for storm water management in Rome.

TSS

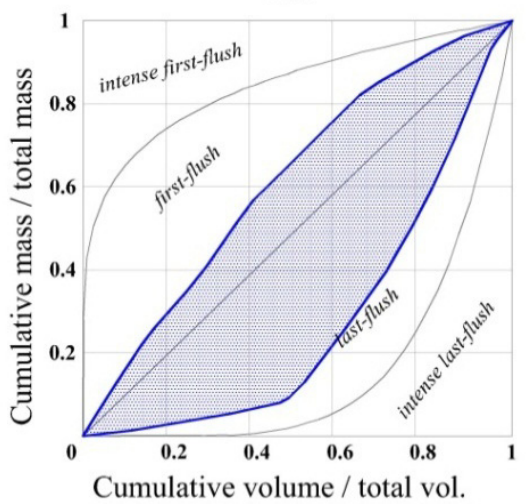

COD

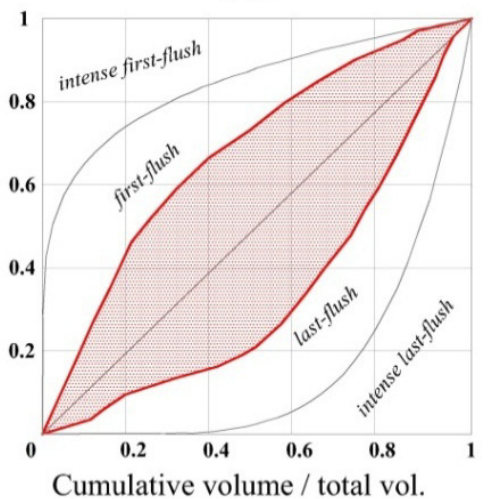

Figure 6: observed range of TSS and COD first-flush intensity for CS basin.

It is finally worth underlying how the proposed RTC strategies require a complex and reliable telemetry system, but introduce little change in the physical actuators and assure fail-safe modifications. Furthermore, compared to the current situation, the discussed mitigation of CSO impact on river quality would be achieved without any significant increase of sewage volume globally pumped towards the WWTP.

\section{The future of RTC for the drainage system of Rome}

The purpose in proposing and evaluating RTC strategies for the large pilot catchment described above was to highlight and quantify the potential benefits of this approach, as well as to favour its application to the experimental catchment and, in the future, to the rest of the drainage system. For this reason, assessing the effects of increasingly more complex forms of control was important to offer the possibility for a gradual implementation. 
Moreover, the feasibility study also involved a more direct approach to develop, based in Acea ATO2 S.p.A.'s control room, an experimental centralised telemetry system dedicated to the pilot catchment, in order to set the basis for advanced real time operations. The main requirements on which the design of such a system is focusing are:

- reliability of equipment and protocol for measuring, transmitting, processing and storing data;

- $\quad$ real time synchronisation, normalisation and processing of data coming from heterogeneous sources (wide range of system measurements, real time monitoring of water quality data, external environmental information, simulation outputs);

- accurate modelling tools suitable for fast-response simulations which use measured data for real time calibration.

Counting on an integrated telemetry system with these features, the application of RTC on the analysed drainage network could progress in steps, with different time horizons. At an initial stage, fast response modelling tools could provide predicted short-term scenarios on which operational staff can make decisions heuristically, although based on automatically evaluated "suggestions". Further phases could involve the partial introduction of fail-safe semi-automated actuators, which would enable their direct testing and would lead the way to more extensive automation in the future.

\section{References}

[1] Lee, H. and Bang, W., Characterization of urban storm water runoff. Water Science and Technology, 3(7), 2000.

[2] Bertrand-Krajewski, J. L., Chebbo, G., Saget, A., Distribution of pollutant mass vs. volume in stormwater discharges and the first flush phenomenon, Water Res., 32(8), 1998.

[3] Campisano, A. and Sanfilippo, U., Controllo in tempo reale dei sistemi di fognatura, Centro Studi Idraulica Urbana, 2011.

[4] Rauch, W. and Harremoës, P., Correlation of combined sewer overflow reduction due to real-time control and resulting effect on the oxygen concentration in the river, Water Science Technology, 37(12), 1998.

[5] Margaritora, G., Spizzirri, M. and Zanobini, A., Historical evolution of urban drainage works for the city of Rome, IAHR International Conference, Venezia, 2007.

[6] Borsànyi, P., Benedetti, L., Dirckx, G., De Keyser, W., Muschalla, D., Solvi, A. et al., Modelling real-time control options on virtual sewer systems, $N R C$ Research Press Web site at jees.nrc.ca, 2008.

[7] DWA - German Association for Water Wastewater and Waste, Framework for Planning of Real Time Control of Sewer Networks, Hennef, 2005. 